\title{
PENINGKATAN KUALITAS DAN PROSES PEMBUATAN BIODIESEL DARI BLENDING MINYAK KELAPA SAWIT (PALM OIL) DAN MINYAK KELAPA (COCONUT OIL) DENGAN BANTUAN GELOMBANG ULTRASONIK
}

\author{
Hantoro Satriadi*), Widayat, Favian Nafiega, Rheza Dipo \\ Jurusan Teknik Kimia, Fakultas Teknik, Universitas Diponegoro, Jl. Prof. Soedarto, SH, Kampus Undip \\ Tembalang, Semarang, Indonesia 50275
}

\begin{abstract}
Abstrak
Keterbatasan solar sebagai sumber energi bahan bakunya tidak dapat diperbaharui menuntut adanya bahan baku alternatif yang dapat diperbaharui dan ramah lingkungan untuk pembuatan biodiesel. Reaksi utama produksi biodiesel adalah esterifikasi dan transestirifikasi yang berlangsung lambat dan membutuhkan banyak katalis dan alkohol. Reaksi yang terjadi belum sempurna dan belum memenuhi standar SNI dan ASTM. Untuk memperbaiki mutu biodiesel serta menghasilkan yield maksimal, maka dilakukan blending bahan baku antara minyak kelapa sawit dan minyak kelapa dan dengan bantuan gelombang ultrasonic. Penelitian ini bertujuan untuk mempelajari pengaruh variabel perbandingan volume minyak kelapa sawit dan minyak kelapa, perbandingan volume methanolminyak, dan persentase berat katalis terhadap minyak terhadap hasil atau yield biodiesel. Alat utama yang digunakan adalah reaktor yang dilengkapi pembangkit gelombang ultrasonic dengan temperature $60{ }^{\circ} \mathrm{C}$, tekanan $1 \mathrm{~atm}$, volume 3 liter, dan frekuensi $28 \mathrm{kHz}$. Variabel proses pada penelitian ini adalah perbandingan volume minyak sawit dan kelapa $2: 1$, 3:1, dan 4:1, pebandingan volume metanol-minyak 0,2:1, 0,25:1, dan 0,3:1, dan persentase berat katalis KOH terhadap minyak 0,3\%, 0,5\%, dan 0,7\%. Hasil penelitian didapat konversi tertinggi dicapai pada variabel perbandingan volume minyak sawit dan kelapa 3:1, perbandingan volume metanol/minyak 0,25:1, dan persentase berat katalis terhadap minyak dengan yield 97,26\%.
\end{abstract}

Kata kunci: biodiesel; gelombang ultrasonik; blending minyak sawit dan kelapa

\begin{abstract}
[A Improvement of Quality and Process for Biodiesel Production from Palm Oil and Coconut Oil Blends with Ultrasound Assisted] Limitations of solar energy as a source of raw material cannot be renewed demands for alternative raw materials that are renewable and environmentally friendly for the manufacture of biodiesel. The main production of biodiesel reaction is esterification and transestirifikasi which runs slow and requires a lot of alcohol and a catalyst. Reactions that happen yet perfect, and has not met the standard of SNI and ASTM. To improve the quality of biodiesel as well as produce maximum yield, then do the blending of raw materials between Palm oil and coconut oil and with the help of ultrasonic waves. This research aims to study the influence of variable ratio of the volume of palm oil and coconut oil, methanol-oil volume ratio, and the percentage of weight of the catalyst to oil to biodiesel results or yield. The main tool used by the reactors are equipped with ultrasonic wave generator temperature $60{ }^{\circ} \mathrm{C}$, pressure $1 \mathrm{~atm}$, 3 liters of volume, and frequency 28 $\mathrm{kHz}$. Process variables in this study is a comparison of the volume of palm oil and coconut 2:1, 3:1 and $4: 1$, ratio volume of methanol-oil $0.2: 1,0.25: 1$, and $0,31: 1$, and the percentage of weight of $K O H$ catalyst to oil $0.3 \%, 0.5 \%$ and $0.7 \%$. Results of the study had the highest conversion achieved at variable volume ratio of palm oil and coconut 3:1, a comparison of the volume of methanol/oil 0.25:1, and the percentage of the weight of oil with the catalyst to yield 97,26\%.
\end{abstract}

Keywords: biodiesel; ultrasonic wave; blending palm oil and coconut oil

\section{Pendahuluan}

Konsumsi minyak solar secara nasional terus meningkat rata-rata $7 \%$ pertahun, diperkirakan tahun

\footnotetext{
${ }^{*}$ Penulis Korespondensi.

E-mail: hantorosatriadi@yahoo.com
}

2020 konsumsi solar mencapai 34 juta kilo liter. Dari konsumsi tersebut, sekitar $40 \%$ adalah solar yang diimpor dari beberapa Negara sejak tahun 2004 Indonesia menjadi net-importer minyak (Agus Sugiyono, 2006). Solar merupakan bahan bakar fosil yang tidak dapat diperbarui sehingga diperlukan upaya untuk mengembangkan bahan bakar pengganti solar yang dapat diperbarui, diantaranya biodiesel. 
Biodiesel merupakan bahan bakar alternatif untuk mesin berbahan bakar diesel dan terbuat dari sumber terbaharui seperti minyak hewan atau minyak nabati. Biodiesel merupakan solusi untuk menggantikan bahan bakar fosil sebagai sumber energi transportasi dunia. Biodiesel bersifat biodegradable, yang artinya hampir tidak mengandung sulfur dan bahan bakar terbarukan. Bahan bakar alternatif ini terdiri dari metil ester hasil transesterifikasi trigliserida atau esterifikasi asam lemak bebas (FFA). Pemerintah telah mengamanatkan penggunaan campuran B2 yaitu campuran dengan kandungan biodiesel 2\% dan solar 98\% untuk sektor transportasi dan berlaku pula secara efektif untuk sektor pertambangan. Dengan berlakunya mandat ini, banyak pelanggan yang menginginkan B2 untuk mendukung inisiatif pemerintah ini (Sheel, 2012).

Reaksi utama produksi bodiesel adalah reaksi esterifikasi dan transesterifikasi. Pada reaksi ini, trigliserida akan bereaksi dengan alkohol seperti metanol atau etanol untuk menghasilkan metil ester dan gliserol sebagai produk samping. Reaksi ini berlangsung relatif lambat sekitar 4-8 jam, membutuhkan banyak katalis dan alkohol, sedangkan reaksi yang terjadi belum sempurna. Selebihnya, peningkatan produk samping memberikan yield yang rendah dari biodiesel dan selama proses tidak semua rantai asam lemak menjadi biodiesel, sehingga dapat mengurangi kualitas yield. Berdasarkan penelitian sebelumnya (Buasri, 2009), diperoleh data yield maksimum $85 \%$ terjadi pada perbandingan etanol dan asam oleic $6: 1$, katalis asam sulfat $1 \% \mathrm{wt}$, dengan waktu 2 jam pada $65^{\circ} \mathrm{C}$. Pada penelitian lainnya (Baharsyah dan Supriyandi, 2013), pembuatan biodiesel dengan menggunakan gelombang ultrasonik diketahui dapat mereduksi waktu reaksi hingga 60 menit. Dari penelitiannya diperoleh yield 95,341\% dengan penggunaan katalis sebesar $1,5 \mathrm{wt} \%$ dan perbandingan alkohol dan minyak 6:1.

Bercermin dari beberapa penelitian terdahulu, melalui penelitian ini diharapkan dapat menghasilkan biodiesel dengan karakteristik yang optimal dan yield maksimum dari proses blending antara minyak kelapa sawit dan minyak kelapa dengan menentukan perbandingan volume minyak sawit dan jarak, persentase berat katalis terhadap minyak, serta perbandingan volume minyak dan metanol yang optimal dalam proses pembuatan biodiesel berbantukan gelombang ultrasonik.

\section{Metode Penelitian}

Penelitian ini menggunakan campuran minyak sawit dan kelapa, dan metanol sebagai bahan baku utama pembuatan biodiesel, sedangkan katalis yang digunakan adalah $\mathrm{KOH}$. Dalam penelitian ini digunakan ultrasonic 6000 sebagai reaktor dimana reaksi yang terjadi reaksi transesterifikasi dengan suhu $60^{\circ} \mathrm{C}$, tekanan $1 \mathrm{~atm}$, dan frekuensi $28 \mathrm{~Hz}$. Variabel penelitian ini adalah perbandingan volume minyak kelapa sawit dan kelapa yaitu $2: 1 ; 3: 1 ; 4: 1$, perbandingan volume minyak dan metanol yaitu 1:0,2; $1: 0,25 ; 1: 0,3$, dan persentase berat katalis terhadap minyak yaitu $0,3 \% ; 0,5 \% ; 0,7 \%$. Setelah dilakukan reaksi transesterifikasi, dilakukan pemisahan produk dan hasil samping berupa gliserol menggunakan dekanter dan distilasi lalu biodiesel dianalisis densitas, viskositas, angka asam, angka penyabunan, dan angka cetane.

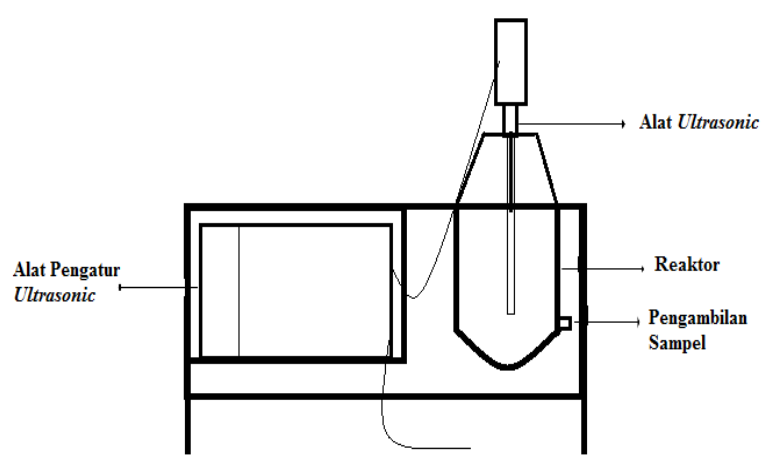

Gambar 1. Rangkaian alat percobaan

\section{Hasil dan Pembahasan}

\subsection{Produk biodiesel}

Untuk mengetahui karakeristik dari produk biodiesel, maka dibutuhkan analisa untuk mengetahui parameter densitas, viskositas kinematis, angka asam, angka setana, bilangan iod, dan angka penyabunan.

Tabel 1. Karakteristik Biodiesel Standar ASTM dan SNI

\begin{tabular}{lccc}
\hline Karakteristik & ASTM & SNI & Hasil \\
\hline Densitas (g/ml) & $0,86-0,90$ & $0,85-0,89$ & $0,89-1,18$ \\
\hline $\begin{array}{l}\text { Viskositas } \\
\text { kinematis (Cst) }\end{array}$ & $1,9-6,0$ & $2,3-6,0$ & $2,89-6,22$ \\
\hline Angka asam & Maks 0,5 & Maks. 0,8 & $0,51-0,79$ \\
\hline Angka setana & Min. 47 & Min. 51 & $64,69-83,12$ \\
\hline Bilangan iod & Maks. 115 & Maks. 115 & $39,34-86,29$ \\
\hline Angka & $\leq 261,26$ & $\leq 261,26$ & $97,05-$ \\
Penyabunan & & & 193,55 \\
\hline
\end{tabular}

Tabel 1 menunjukkan bahwa karakteristik produk biodiesel sebagian besar telah memenuhi standar biodiesel internasional ASTM dan SNI. Untuk parameter densitas, viskositas kinematis, angka asam, angka setana, bilangan iod, dan angka penyabunan. Berdasarkan parameter-parameter diatas, masih ada sebagian produk yang belum memenuhi standar SNI/ASTM maka setelah dipisahkan sabunnya, dibutuhkan proses transesterifikasi lanjut.

\subsection{Hubungan antara variabel dengan angka} cetane

Setiap variabel akan dihitung angka cetane menggunakan rumus:

Angka cetane $(Y)=46,3+\frac{5458}{S N}-0,225 x I V \ldots(1)$ 
Hubungan variabel dengan yield dapat dilihat pada Tabel 2.

Tabel 2. Angka cetane tiap variabel

\begin{tabular}{llllll}
\hline Run & Block & $\mathbf{X}_{\mathbf{1}}$ & $\mathbf{X}_{\mathbf{2}}$ & $\mathbf{X}_{\mathbf{3}}$ & $\mathbf{Y}$ \\
\hline 1 & 1 & -1 & -1 & -1 & 65,65 \\
2 & 1 & -1 & -1 & 1 & 64,69 \\
3 & 1 & -1 & 1 & -1 & 65,85 \\
4 & 1 & -1 & 1 & 1 & 69,71 \\
5 & 1 & 1 & -1 & -1 & 68,77 \\
6 & 1 & 1 & -1 & 1 & 70,82 \\
7 & 1 & 1 & 1 & -1 & 72,30 \\
8 & 1 & 1 & 1 & 1 & 71,10 \\
9 & 1 & 0 & 0 & 0 & 68,30 \\
10 & 2 & -1.76 & 0 & 0 & 70,77 \\
11 & 2 & 1.76 & 0 & 0 & 83,12 \\
12 & 2 & 0 & -1.76 & 0 & 70,60 \\
13 & 2 & 0 & 1.76 & 0 & 69,78 \\
14 & 2 & 0 & 0 & -1.76 & 73,71 \\
15 & 2 & 0 & 0 & 1.76 & 65,80 \\
16 & 2 & 0 & 0 & 0 & 67,17 \\
\hline
\end{tabular}

Keterangan :

$\mathrm{X}_{1}=$ Perbandingan volume minyak sawit dan kelapa

$\mathrm{X}_{2}=$ Perbandingan mol metanol dengan minyak

$\mathrm{X}_{3}=$ Persen katalis pada minyak

$\mathrm{Y}=$ Angka cetane biodiesel

Untuk mengetahui variabel yang paling berpengaruh, dilakukan pengolahan data dengan menggunakan software statistic dan persamaan model matematis secara umum untuk proses optimasi. Dalam penelitian ini digunakan 3 variabel, sehingga persamaan polynomialnya menjadi:

$Y=67,51084+5,46657 X_{1}+4,76790 X_{1}^{2}+$ $1,06645 X_{2}+0,42540 X_{2}^{2}-1,43465 X_{3}+$ $0,14575 X_{3}^{2}-0,35250 X_{1} X_{2}-0,51250 X_{1} X_{3}+$ $0,39250 X_{2} X_{3}$

Dari persamaan tersebut bisa dilihat bahwa koefisien $\mathrm{X}_{3}$ bertanda positif dan memiliki nilai yang terbesar dan paling berpengaruh.

\subsection{Analisa varian}

Analisa Varian bertujuan untuk mengetahui variabel yang berpengaruh dan interaksi antar variabel yang berpengaruh. Koefisien juga dievaluasi dari varians. Hasil di Tabel 3 menunjukkan bahwa satu variabel dan kuadrat variabel memiliki nilai $F$ yang lebih besar daripada $p$ harga sehingga merupakan variabel yang berpengaruh. Untuk variabel interaksi memiliki nilai $\mathrm{F}$ kurang dari nilai $p$ sehingga dapat direjeksi dari model matematika awal (Widayat et al.,
2012). Model matematika baru menjadi Persamaan (3).

Tabel 3. Analisa varian

\begin{tabular}{lrlrll}
\hline Faktor & \multicolumn{1}{l}{ SS } & df & \multicolumn{1}{l}{ MS } & F & p \\
\hline $\mathrm{X}_{1}$ & 106,2519 & 1 & 106,2519 & 6,950367 & 0,038729 \\
\hline $\mathrm{X}_{1}{ }^{2}$ & 59,3222 & 1 & 59,3222 & 3,880506 & 0,096364 \\
\hline $\mathrm{X}_{2}$ & 4,0438 & 1 & 4,0438 & 0,264521 & 0,625419 \\
\hline $\mathrm{X}_{2}{ }^{2}$ & 0,4722 & 1 & 0,4722 & 0,030890 & 0,866267 \\
\hline $\mathrm{X}_{3}$ & 7,3181 & 1 & 7,3181 & 0,478705 & 0,514877 \\
\hline $\mathrm{X}_{3}{ }^{2}$ & 0,0554 & 1 & 0,0554 & 0,003626 & 0,953937 \\
\hline $\mathrm{X}_{1} \mathrm{X}_{2}$ & 0,2485 & 1 & 0,2485 & 0,016256 & 0,902711 \\
\hline $\mathrm{X}_{1} \mathrm{X}_{3}$ & 0,5253 & 1 & 0,5253 & 0,034363 & 0,859045 \\
\hline $\mathrm{X}_{2} \mathrm{X}_{3}$ & 0,3081 & 1 & 0,3081 & 0,020155 & 0,891752 \\
\hline Error & 91,7234 & 6 & 31,844 & & \\
\hline Total & 288,3330 & 15 & & & \\
SS & \multicolumn{7}{l}{} & \\
\hline \multicolumn{7}{l}{$67,51084+5,46657 X_{1}+4,76790 X_{1}^{2}$} & $\ldots(3)$
\end{tabular}

\subsection{Variabel berpengaruh}

Diagram Pareto adalah sebuah distribusi frekuensi sederhana (histogram) dari data yang diurutkan berdasarkan kategori dari yang paling besar sampai yang paling kecil. Diagram ini didasarkan atas prinsip yang menyatakan bahwa ada banyak faktor yang mempengaruhi sesuatu tetapi hanya beberapa faktor penting saja yang diperhitungkan yakni faktorfaktor yang menimbulkan dampak yang paling penting (Montgomery, 1991).

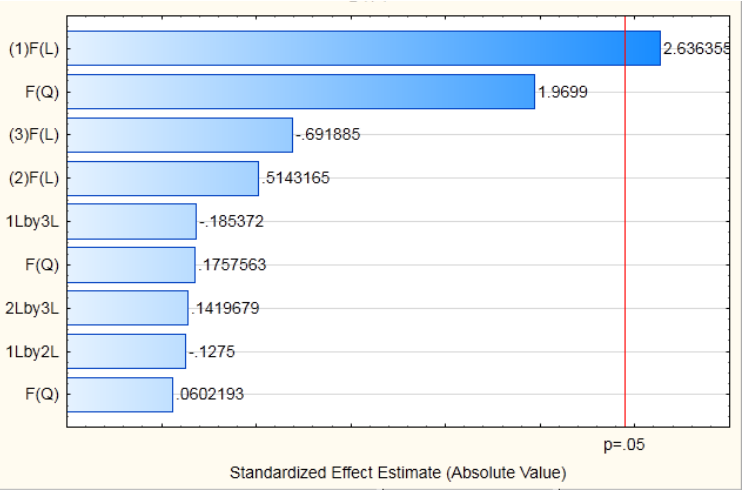

Gambar 2. Diagram Pareto

Grafik Pareto menunjukkan bahwa harga efek variabel yg melewati garis pada $p=0.05$ merupakan variabel yang sangat berpengaruh terhadap proses (Montgomery, 1991) yaitu pada penelitian ini satu variabel dan kuadrat variabel pada pebandingan volume minyak $\left(\mathrm{X}_{1}\right.$ dan $\left.\mathrm{X}_{1}^{2}\right)$. Nilai efek dari variabel yang jauh dari garis $\mathrm{p}=0,05$ merupakan variabel berpengaruh yang dapat diabaikan (Giovanilton, 2011) yaitu interaksi antara variabel seperti ), perbandingan volume minyak/methanol $\left(\mathrm{X}_{2}\right.$ dan $\left.\mathrm{X}_{2}{ }^{2}\right)$, dan kadar katalis terhadap berat minyak $\left(\mathrm{X}_{3}\right.$ dan $\left.\mathrm{X}_{3}^{2}\right)$, rasio volume minyak sawit dan minyak kelapa perbandingan volume minyak dengan metanol $\left(\mathrm{X}_{1} * \mathrm{X}_{2}\right)$, perbandingan volume minyak dengan metanol-kadar katalis terhadap massa minyak 
$\left(\mathrm{X}_{2} * \mathrm{X}_{3}\right)$, dan rasio massa minyak sawit dan minyak jarak - perbandingan volume minyak dengan methanol $\left(\mathrm{X}_{1} * \mathrm{X}_{3}\right)$ karena pengaruhnya tidak mengakibatkan peningkatan nilai yang signifikan. Jadi pada penelitian ini interaksi antara tiap variabel tidak berpengaruh.

\subsection{Hasil optimum}

Nilai kritis (critical value) suatu statistik uji adalah nilai yang begitu ekstrem sehingga probabilitas untuk mendapatkan nilai tersebut atau yang lebih ekstrem. Dengan demikian bahwa dalam kaidah pengambilan keputusan (decesion rule) dapat dinyatakan menurut nilai-nilai kritis (Saputra, 2013). Nilai kritis dari variabel percobaan kami dapat dilihat pada Tabel 4 .

Tabel 4. Nilai Kritis

\begin{tabular}{|l|l|l|l|}
\hline Factor & $\begin{array}{l}\text { Observed } \\
\text { Minimum }\end{array}$ & $\begin{array}{l}\text { Critical } \\
\text { Value }\end{array}$ & $\begin{array}{l}\text { Observed } \\
\text { Maximum }\end{array}$ \\
\hline$X_{1}$ & $-1,76$ & 0,02363 & 1,76 \\
\hline$X_{2}$ & $-1,76$ & $-9,32680$ & 1,76 \\
\hline$X_{3}$ & $-1,76$ & 17,52113 & 1,76 \\
\hline
\end{tabular}

Pada Tabel 4 dapat disimpulkan bahwa nilai kritis untuk perbandingan volume minyak sawit dan kelapa $\left(\mathrm{X}_{1}\right)$ adalah 0,02363 maka diperoleh nilai optimum 1:3,02363; perbandingan volume minyak dengan metanol $\left(\mathrm{X}_{2}\right) \quad-9,32680$ diperoleh nilai optimum 1:-0,21634; dan berat katalis $\left(\mathrm{X}_{3}\right)$ adalah 17,52113 diperoleh nilai konsentrasi katalis sebesar $4 \%$.

\section{Kesimpulan}

adalah:

Kesimpulan yang diperoleh dari penelitian ini

1. Pada penelitian ini didapatkan yield tertinggi sebesar 83,12 dengan perbandingan volume minyak kelapa sawit dan kelapa 4,764:1, jumlah katalis $0,5 \%$ massa minyak, dan perbandingan volume metanol-minyak $0,25: 1$.

2. Model persamaan matematika untuk mencari yield biodiesel adalah

$$
Y=67,51084+5,46657 X_{1}+4,76790 X_{1}^{2}
$$

3. Berdasarkan analisa viskositas, densitas, angka asam, angka penyabunan, bilangan iodin, angka cetane, dan analisa FAME menggunakan GC menunjukkan bahwa sebagian besar produk biodiesel telah memenuhi standar SNI dan ASTM.

\section{Ucapan Terima Kasih}

Ucapan terima kasih disampaikan kepada Laboratorium Pelayanan Terpadu (C-Biore) dan Teknik Kimia UNDIP atas kontribusinya sebagai tempat dilakukannya penelitian ini.

\section{Daftar Pustaka}

Baharsyah, Aji dan Supriyandi. (2013). "Optimasi Proses Pembuatan Biodiesel Berbantukan Gelombang Ultrasonik dari Blending Minyak Kelapa Sawit (Crude Palm Oil) dan Minyak Jarak (Jatropha Curcas Oil). Teknik Kimia. FT UNDIP. Semarang.

Buasri, Achanai., dkk. (2009). Biodiesel from Crude Palm Oil with a High Content of Free Fatty Acids and Fuel Properties: Faculty of Engineering and Industrial Technology. Silpakorn University. Thailand.

Montgomery, D. C. (1991). Design and analysis of experiments, 3rd ed. New York: Wiley.

Saputra, Roni. (2013). Statistik Terapan Dalam Ilmu esehatan Masyarakat. Stikes Printis. Sumatera Barat.

SNI 04-7182-2006 Biodiesel.

Sugiyono, Agus. (2006). "Peluang Pemanfaatan Biodiesel dari Kelapa Sawit Sebagai Bahan Bakar Alternatif Pengganti Minyak Solar di Indonesia". Prospek Pengembangan Bio-fuel Sebagai Bahan Bakar Minyak. Indonesia.

Widayat, Satriadi Hantoro, Yuariski, Murwono., (2013). Biodiesel Production From Bulk Frying Oil With Ultrasound Assisted. Teknik Kimia Universitas Diponegoro. Semarang. 